\title{
Advanced Mathematics Teaching Reform based Computer Technology
}

\author{
Zhang Xue Fu \\ (He Xi University, Zhangye Gansu 734000)
}

\begin{abstract}
Keywords: Computer technology; advanced mathematics; Teaching reform
\end{abstract}
\begin{abstract}
In the 21st century in China, multimedia technology and network technology have changed social production and development model and have also changed people's life style and learning style. Computer technology not only promotes knowledge economy development in our country, improves international competitiveness in China, but has a huge influence on the education domain of our country. Computer technology effectively expands the research field, methods and using range of math subjects, and has become a bright spot and innovation in advanced mathematics teaching reform in our country. This article focuses on advanced mathematics teaching reform under the background of computer technology. Advanced mathematics teachers should realize the necessity of the combination of computer technology and advanced mathematics teaching reform, and starting from the theoretical analysis combined with both sides, put forward the strategies method of the combination.
\end{abstract}

Advanced mathematics is the basic theory class in colleges and universities. Students can gradually develop their own abstract generalization ability and logical thinking ability and so on by learning this course. Advanced mathematics can pave the way for the follow-up professional courses and fundamental courses. Mathematics provides a powerful support for high-tech development. Contemporary science and technology development cannot leave mathematics, so colleges and universities should improve students' mathematical quality, cultivate students' mathematics comprehensive application ability, positively respond to the new curriculum reform requirements and standards and innovate advanced mathematics teaching method and means.

\section{THE NECESSITY ANALYSIS OF ADVANCED MATHEMATICS TEACHING REFORMING BASED ON COMPUTER TECHNOLOGY}

In recent years, China's computer information technology gets rapid development, and computer technology has now penetrated in various fields of the society. Mathematics is the theoretical basis and the support of computer rapid development and promotes the development of computer science. Many world famous mathematical foundation leaders in the field of computer science and mathematics are very good. They are good at thinking and putting forward new subjects and are innovative and creative. Universities should strengthen the combination efforts of computer technology and advanced mathematics, and lay a good foundation for advanced mathematics development. Most of teaching method of advanced mathematics education in colleges and universities lag behind in our country. Teaching shortcomings are prominent, which are mainly manifested in the following aspects: advanced mathematics teaching adopts single method of teaching. Traditional cramming education way takes simple teaching tools: a piece of chalk, a blackboard, and a teacher just complete one section of advanced mathematics course and modern computer technology and means are not fully used in advanced mathematics teaching. Most of advanced mathematics teachers are not very clear or familiar with the relationship between advanced mathematics and computer technology. They are not clear about the role of computer technology and basic courses in advanced mathematics, so in advanced mathematics teaching, they cannot give vivid teaching with the aid of computer technology [1]. The examination mode of advanced mathematics teaching in colleges and universities falls behind and lack of creative practice activity. Advanced mathematics teaching reform based on computer technology is urgently needed and is imperative. 


\section{THE THEORETICAL FOUNDATION OF COMPUTER TECHNOLOGY AND ADVANCED MATHEMATICS TEACHING REFORM COMBINATION}

\section{A. The theoretical basis of computer technology and advanced mathematics teaching reform combination}

The integration development of computer technology and advanced mathematics curriculum has a certain theory basis. The education learning theory provides the basic theoretical basis for advanced mathematics and computer technology integration. Let's make detailed analysis of the theoretical foundation of computer technology and advanced mathematics teaching reform combination. The first is behavioral learning theory. The theoretical content is that teachers prepare before class and stimulate students by using various forms of multimedia means. Gently lead students into the ready state of learning and promote students to recall the old knowledge and predict new knowledge. Teachers properly using computer technology in teaching process can also give students a variety of forms of feedback information, feedback to the student by answering the questions, and give praise and encouragement to enhance students learning enthusiasm; Teachers also should do a good job of giving tips and guidance in students' daily learning to help students gradually develop good study habits. The second is cognitive learning theory, and theory content is that teachers not only transfer knowledge, but help guide the student to become the subject of learning, make the students obtain knowledge autonomously. Teachers also should make a detailed analysis on students' features and teaching content. With the aid of multimedia information technology, carry out advanced mathematics course. Take independent inquiry learning way; adjust cognitive learning structure to better understand the knowledge according to the actual situation. The third is constructive learning theory. This theory argues that teachers' teaching and students learning are a construction process. Not only construct new knowledge, but reform and restructure the original experience and it holds that advanced mathematics teaching mode based on computer technology should take students as the center, create a certain learning scenarios to create conditions for students' initiative and enthusiasm. Promote meaning construction and better solve practical problems. In this paper, the main theory of advanced mathematics teaching reform is constructive learning theory.

$B$. The main teaching mode which combines computer technology and advanced mathematics

Advanced mathematics teaching mode with computer technology has been changed. The original teaching mode already cannot adapt to social development and the progress need of science and technology, and is not consistent with quality education promoted in our country. The combination teaching mode of computer technology and advanced mathematics mainly can be built from four aspects: first is to take computer technology as a teaching tool; the second is to take it as a teaching resource; the third is to take it as a teaching environment; the fourth is to use computer technology to promote cooperative learning teaching. It can be concluded that combining teaching mode of computer technology and advanced mathematics course is built with the help of constructive theory point of view. Constructive theory holds that to construct the understanding of new knowledge, establish a link between new knowledge and old knowledge and make the knowledge structure corresponding to them. Build and form a new cognitive structure through reform, reorganization or restructure. Introduce computer technology in advanced mathematics teaching and build a new mathematics teaching mode under the precondition of old and new mathematical teaching model integration thus to promote students' learning efficiency [3]. Math problems research-style teaching mode based on computer technology should mainly manifest the process of mathematics learning and exploring. Teachers take the finish of concrete mathematics teaching tasks as purpose, and students are always in the process of finding problems, using mathematical methods to ask questions, independent thinking and solving problems under teacher's leading. The process of mathematical problem exploring instructional mode is helpful for students to form main body consciousness. Students in the process also get math thinking, and receive individual development. Students are no longer closed passive learning, and they have the right to have interest in proposing math problems, positively think of solutions and then extend further problems. While using this kind of teaching mode, teachers should realize that problem is the heart of mathematics. Only with 
questions would one think and can have problems. So advanced mathematics teachers should consider students' cognitive structure based on teaching goal. Put advanced mathematics' teaching content in the center and use computer technology and tool to design problems. Create a good thinking situation for students and motivates students' active thinking and exploration to discover rules and solve problems [4]. Network environment under computer technology gives students opportunities and space of full development and independent activity, which enables them to use computer for mathematical modeling and solve real life problems.

\section{THE COMBINATION STRATEGY ANALYSIS OF COMPUTER TECHNOLOGY AND ADVANCED MATHEMATICS TEACHING REFORM}

Under the background of new curriculum reform, many colleges and universities advanced mathematics teaching reform is in full swing in our country and has obtained good effect. The core content of advanced mathematics teaching reform is to make better combination of advanced mathematics and practical application and professional demand. Teachers should actively improve innovation, use new teaching methods and make some corresponding teaching materials books. Here college computer major is taken for example for detailed analysis.

\section{A. The reform of teaching materials}

Computer major in most colleges generally uses engineering mathematics teaching material in common colleges and universities. The teaching content is detailed and classic but lack corresponding computer related content, so its usefulness is also poor. Colleges should carry out questionnaire among the students and work out the effective implementation of advanced mathematics teaching reform from the actual situation. In the process of advanced mathematics teachers' performing the reform, make good coordination and communication with computer teachers and build a special group of advanced mathematics teaching reform. According to students' actual professional needs and interests, take practical as principle, and develop computer professional teaching material for advanced mathematics on the basis of further details about the major. Colleges and universities can complete it independently, or do it with the same type colleges and universities cooperation. At the same time, other majors' advanced mathematics teaching in colleges and universities can take this approach for teaching material reform to promote advanced mathematics teaching practicability [5].

\section{$B$. The reform of advanced mathematics' teaching content}

Advanced mathematics teachers tend to focus on skills or proposition proof in practical teaching and rarely mention the quality connotation and characteristics of modern mathematics. They do not more specifically summarize the existing problems, and computer algorithm thought is not analyzed and elaborated in advanced mathematics teaching in classroom. Many computer professional students cannot correctly and objectively realize the importance of learning advanced mathematics. Advanced mathematics teachers teach the same knowledge only from the angle of mathematical analysis, so students cannot apply advanced mathematics knowledge to actual computer algorithm. There is a disconnection phenomenon occurring from a mathematical method to a computer algorithm. This kind of phenomenon is very common. For example, when advanced mathematics teachers are teaching derivative chapter, they just put forward that the curve tangent slope at point

$\left(\mathrm{x}_{1}, f\left(x_{1}\right)\right)$ is the derivative value of it, then introduce the tangent equation of point $\mathrm{x}_{1}$ and normal equation solving method when proposing derivative geometric meaning. These are the most basic derivative meanings. For computer professional students, the more important is to derive relation formula by the meaning. Then the advanced mathematics teachers extend explanation: derivative has a geometric meaning, so here give it some limited conditions, and after appropriate selection of the initial value, we may draw a point column $\left\{\mathrm{x}_{i}\right\}$, this point series is got from $\mathrm{x}_{i+1}=x_{i}-\frac{f\left(x_{i}\right)}{f^{\prime}\left(x_{i}\right)}$, and there are limits $\mathrm{x}^{*}=\lim _{i \rightarrow \infty} x_{i}$, where $\mathrm{x}^{*}$ is the root of the equation $\mathrm{f}\left(\mathrm{x}_{1}\right)=0$. Then computer professional students can more easily transform their ideas of iteration algorithm to 
language Newton iterative formula, so advanced mathematics practicality is stronger, which also greatly improves its alignment with computer professional course [6]. In addition, advanced mathematics teachers can also use computer technology to carry out mathematical modeling and mathematics experiment teaching to cultivate students' thinking quality.

C. Carry out stratification teaching

College enrollment expansion in recent years makes bigger students' individual differences, and students' mathematical basis difference is bigger. So advanced mathematics teachers should take stratified teaching. Advanced mathematics teachers should first divide course content into different levels suitable for students, generally basic level and improved level. If conditions permit, subdivide the contents into extension levels associated with various majors. Different levels advanced mathematics teaching are for different students' mathematical basis. The second is to divide students into several levels, considering three factors: the first is mathematical basis based on their placement test scores and university entrance exam, etc.; The second is a reference of students interests and hobbies; The third is based on students majors, adjust according to the requirements of academic disciplines, promote students of all levels actively to involve in advanced mathematics studies. Advanced mathematics teachers should teach according to their aptitude by using flexible teaching methods. Create lively and interesting teaching scene to stimulate students learning enthusiasm and interest. Reform and innovate teaching method to improve advanced mathematics teaching quality and level in colleges.

\section{CONCLUSION}

Advanced mathematics teaching reform based on computer technology is a significant and huge system engineering, and it cannot be finished in short term. Advanced mathematics teachers in colleges and universities should actively participate in teaching reform and take a variety of means to mobilize students' learning. Combining with the characteristics of specific professional disciplines, flexibly and practically develop advanced mathematics teaching.

\section{REFERENCES}

[1] Liu Jiao. Mathematical knowledge skills and related information technology research based on the higher vocational students' vocational development [D]. East China Normal University, 2014.

[2] Li Bingfeng. The application of computer technology in advanced mathematics teaching [J]. Journal of Information Science and Technology, 2010, 35, 96.

[3] Zhang Geng, Duan Yuan. Applied undergraduate colleges computer professional teaching reform exploration of advanced mathematics course ---- take mathematical modeling as the breakthrough point [J]. Journal of New Curriculum Research, 2015-01:38-40.

[4] Li Ruijuan, Xu Haidan. Advanced mathematics course reform research based on computer technology in medical colleges and universities [J]. Science Tribune, 2015: 56-57.

[5] Huang Kuanna. The practice research of information technology and advanced mathematics curriculum integration [D]. Southwest University, 2009.

[6] Han Xue. Computer major advanced mathematics teaching reform [J]. Journal of New Technology and New Products in China, 2009, 13:215. 